temperature, and in process of time loss of appreciation of sensations of cold and warmth results. There is no definite intellectual failure, therefore probably no numerical atrophic changes in the cerebral nerve cells; the nerve force is only diminished in quantity and in the rate of its discharge.

In the contemplation of this disease one is struck by the remarkable analogy to certain lesions of the sympathetic system, and the idea suggests itself that myxoedema may result from a paresis of this system ; in support of which I would draw attention to the following facts:- -1 . The sphygmographic tracing in this case is exactly similar to that produced experimentally by passing a strong continuous current along the middle and inferior cervical ganglia of the sympathetic; when the line of ascent is rendered more oblique, the pointed apex almost entirely disappears, and the duration of the systole relatively to the diastole is greatly diminished. There is also a diminution in the pulse-rate of from four to sixteen beats (Eulenberg and Guttmann). 2. Graves's disease, or exophthalmic goitre, is characterised by increased rapidity of cardiac action, enlargement of the thyroid, prominence of eyeballs, dilated pupils, increased cutaneous secretion, and irritability of temperament. This is the very antithesis of what obtains in myxcedema, in which diminished cardiac action, atrophy of the thyroid, retraction of eyeballs, contracted pupils, diminished cutaneous secretion, and marked tranquillity are prominent symptoms. Again, Graves' disease is, I believe, confined to early adult life. Myœdema occurs at a more advanced age, when the store of vitality is becoming exhausted and degenerative changes ensue. Furthermore, exophthalmos has been induced experimentally by the slight stimulation of the cervical ganglia of the sympathetic in animals. 3. After the complete removal of the thyroid body, a state in every way similar to myxœdema has been found to supervene, named by Prof. Kocher "Strumipriva." May not this be accounted for by the section of the numerous branches coming from the middle and inferior cervical ganglia of the sympathetic (especially the former) of either side to this gland, which intercommunicate in its substance, and which are removed with the gland, thereby causing degenerative changes in the corresponding ganglia? These branches must form, to a large extent, the main line of connexion between the middle and inferior cervical sympathetic ganglia of the one side and the other. As a consequence of degenerative changes in the ganglia, the heart's action would be rendered slower, through the loss of power in the cardiac branches of the sympathetic coming from these ganglia, while the regularity of its action would not be interfered with, that being dependent on its special ganglia. 4. Excessive stimulation of the middle and inferior cervical ganglia of the sympathetic results, through the medium of the cardiac cervical sympathetic branches, in retardation of the heart's action, its regularity, for the reason above stated, being unimpaired. 5. Jaborandi has been found of service in myxodema. Now, jaborandi acts by stimulating the sympathetic system, and probably in this disease by restoring somewhat the rapidity of the circulation and respiration, the tissue changes and temperature, thereby improving the quality of the blood. 6. In the cases which have resulted in "Strumipriva" the thyroid has been removed for advanced disease of its tissue. Surely no great change of the blood and tissues can result from the removal of an organ rendered comparatively useless by disease. I would, in connexion with the thyroid, note the fact of its large size in the new-born infant (at which period the sympathetic exercises greater sway), when the proportion to the body is as 1 to from 240 to 400 , whereas in the adult the proportion is 1 to 1800 . This is not without its significance, as showing the intimate connexion of this body with the sympathetic ganglia. 7. The ascertainable cause of myxcedema is generally, as in this case, some nervous depression, worry, domestic anxiety or affliction, pecuniary losses, \&c.

In the care of $A$. $R$ - we have the sequence, worry, nervous depression in a neurotic subject (she sulfered from palpitation and debility in early life), erysipelas of face and neck, neuraloic pains, myxodema Brown-Séquard has shown that paralysis of the sympathetic of the same side follows irritation of the surface of the brain. 8. In many of these cases of myxodema there is an early stage of the disease nearly allied to exophthalmic goitre. There is, then, a striking aualogy between myxœdema presumably affecting the sympathetic system and general paralysis of the insane

affecting the cerebro-spinal grey matter. We can compare them side by side, thus :-

$$
\text { Cerebro-spinal. }
$$

(General Paralysis of the Insane.)

1. Stage of increased function and cell nutrition, with grandiose mania.

2. Stage of commencing nerve atrophy and diminished function, with excessive formation of fat in the connective tissues.

3. Stage of advanced atrophic nerve change, with dementia and paresis.

4. Neurotic origin, prolonged course, temporary periods of improvement, but fatal issue.

What connexion can there be between paresis of the cer vical sympathetic and the deposition of mucin in the tissues?

It seems to me that the following sequence of events obtains, each bearing to that succeeding it the relation of cause to effect- $(a)$ some neurotic influence in a person pre disposed to its agency; (b) atrophic lesions of the cervical sympathetic ganglia, with paresis of their cardiac branches (c) retardation of the heart's action and blood flow, with alteration in the composition of the blood consequent thereon the formation of mucin as a retrograde derivative of blood albumen, this mucin being held in solution by the alkaline blood ; $(d)$ transudation of mucin from the vessels, deposition of it in the external vascular tunic and in the connective tissues.

In conclusion, I would state that I merely offer these sug. gestions as the outcome of the study of the case which has been under my individual notice, knowing full well the many difficulties that beset the paths of all scientific investigations, but trusting these ideas may be of some slight service in the elucidation of this interesting disease.

Chartham, near Canterbury.

\section{A CASE OF MYXCEDEMA.}

BY ERNEST H. JACOB, M.D., M.A., ASSISTANT-PHYSICIAN TO THE LEEDS INFIRMARY,

E.R-, aged thirty-two, applied for treatment at the Leeds Dispensary on Sept. 26th, 1883, complaining of swelling of the feet and abdomen. She was visited at home for a short time, and attended as out-patient on Nov. 6th, when the following notes were taken. She had good health till four years ago, when soon after a confinement she noticed some general swelling of the body, and she began to lose strength. This continued, without causing much trouble, for about two years, when she had a miscarriage. Since then the symptoms have been more marked. There has been a general swelling of the face, abdomen, and legs, the feet becoming slightly ædematous at night. Her friends have observed a great change in the appearance of her face. She has become very deaf, and her memory has somewhat failed; she has suffered severely from occipital headache, and her hair has fallen. There is no history of syphilis. On examination, she was about five feet high, of somewhat squat build; complexion sallow, with faint bluish-red flush on cheeks ; lips tbick and pouting and rather blue. There was an elastic fulness well marked over face and neck, especially in the supra-clavicular region, but no real cedema. Her hands and forearms were covered with a thick, hard skin, very rough; the skin of the palms was fissured, and she complained that she could not make her hands look clean by washing. This was less marked in the legs and feet. Her abdomen was prominent and the walls thick, but nothing abnormal could be felt. She never perspired, and always felt cold. The digestion was good, the tongue fairly clean, and the bowels somewhat

1 A paper read before the Leeds and West Riding Medico.Chirurgical Society. 
confined. The urine was generally of low spesific gravity, rather copious, and contained less urea than usual; occasionally a.trace of albumen was found. She was moderately intelligent, but there were signs of general weakness in the mervous system. Speech was slow, and somewhat laboured. She said she oecasionally "Ioses herself" for a few seconds. The patient was very deaf; she could hear a loud voice, but not a watch pressed to her ear. The reflexes were normal. There was some general loss of cutaneons sensibility, and the floor felt soft as she walked. She could stand with her eyes shut. The hands felt cold, numbed, and painful. There were no marked signs in the heart and lungs. No thyroid could be felt. She was treated at first with iodide of potassium, under which she seemed to improve, and said she felt steadier. She was then given nitrate of pilocarpine in doses of one-eighth of a grain, which caused some slight moisture on the skin, and appeared to increase her comfort considerably, but of late she has somewhat relapsed, and I do not think she is much better than when I first saw her. She complains principally of severe occipital headache.

Leeds.

\section{A CASE OF EPILEPTIC AUTOMATISM.}

\section{BY SOLOMON C. SMITH, M.D.,} SURGEON TO THE HALIFAX INFIRMARY.

THE following is an interesting example of epileptic antomatism :-

A young man has for four years been subject to attacks of petit mal. He does not fall, but seems to "fix" his eyes, and sometimes walks forwards, or sideways, at others sits down, and generally ends by going to sleep. There are neither convulsions nor frothing at the mouth, nor tongue biting. The only warning is that he suddenly begins to wonder whether he is going into an attack, and then he loses consciousness. He does not think he ever dropped anything out of his hand, but he has spilt tea out of a cup. In some of the attacks he will stop what he is doing and seem to "study" for a time, but in others he will go on doing what he was engaged in at the time.

A. On one occasion, while alone in the house, he had been playing the oboe, and was just turning over some music when he lost himself, and knew nothing more for an hour and a quarter (he happened to know the time); when consciousness returned he was lying on the sofa still alone in the house. He, however, must have, during the state of unconsciousness, put the oboe properly away in its case and taken out the reed, for it was uninjured in its place when he came to himself. Now, this taking the reed out of an oboe is an operation requiring very delicate manipulation.

$B$. Another day he was with several musical friends. I think he had been accompanying some of them on the piano. $\mathrm{He}$ was standing at the table turning over some pieces of music when they saw him go into an attack. While it was obvious to them that he was in a fit, for they had seen him before, he took up a piece of music, went to the piano, and played it; he was quite unconscious afterwards of having done this.

$C$. In his father's mill there is a machine for winding warps, which is not under the special care of anyone, for, when started, it works for some time by itself; but occasionally a warp breaks, and when this takes place anyone who happen to see the broken end of the warp hanging down stops the machine, "piecens"-i.e., joins - the ends, and starts the machine again. Now, one day his father and others saw him go into an attack ("fix" his eyes and walk forward) and while he was in it he passed this machine, in which a broken warp was at that moment hanging down. He stopped the machine-which is a peculiarly complex action, for it must not be stopped suddenly, but has to be let down or "slowed" by degrees - he tied the broken ends, and then started the machine a gain. All this he did while obviously quite unconscious, and then he passed into the usual drowsy ending of the attack.

These are good illustrations of the complexity of those antomatic actions which often occur during epileptic unconsciousness. It is important, however, to recoguise that they did not constitute the fit, but took place in spite of it; it was in no sense purposive epilepsy ; the patient's actions were purely automatic, occurring in response to stimuli reflexed through centres lower than those involved in the discharge. If this be limited to parts essential to higher consciousness only, and lower areas are left untonched, these, being freed from control, will, according to Dr. Hughlings Jackson, act automatically, sometimes with even hyperphysiological activity, in response to any stimuli which fall in their way, which may, as was possibly the case in $A$, be the remains of intentions already cerebrally formulated, or may be sense impressions received while in the uncorrscious condition, as was certainly the case in $C$. The apparent rationality of the actions is confirmatory of the opinion expressed in the recent Croonian lectures-that in the " dissolution" of epileptic discharge "the lower level of evolution remaining - the then highest level-is of some part of the highest centres," that the middle and lowest centres are of course in activity, " but are put in activity by what remains of the highest." $A$ illustrates the great delicacy of touch and manipulation which may be exercised; $B$, that such an art as music may be practised, an art requiring the use of memory in a high degree; and $C$, that a sensory impression received dur. ing the condition of automatism may set up a fresh and most elaborate series of movements, which are performed swith accuracy and perfect appropriateness. : These have been spoken of as post-epileptic, the suggestion being that the automatism occurs after the paroxysm, but as somewhat similar phenomena (i. $e_{1}$, non-convulsive, apparently. purposive acts) sometimes occur very early in the attack, even before a convulsion, we must believe that all that is necessary for their production is that discharge should occur in those nervous structures whose interlacements form the physical substraturn of consciousness, while the reflex circles (or more truly mazes) required for the particular automatic actions of the case are intact, whether as the result of nonimplication or of prior recovery is a matter of indifference, as it also is whether the discharge in the upper layers still goes on or not. There is this great difference, however, between the actions at the two extremes of the attack; in those which are post-epileptic external suggestions obviously play a part, so that the resulting phenomena vary in the different paroxysms of the same individual, but the early movements which take place at the commencement are apt to be repeated each time in nearly the same form, and so to seem really to constitute part of the fit itself. When, for example, a girl rushes into the słreet tearing at her dress and shrieking that she.has rats inside her, and then falls into stupor, or when a man while conversing suddenly begins to undress, and this ends in a convulsion, and when in each case the same sequence of events recurs every time, the repetition of the same phenomena negatives their dependence on external and therefore varying stimuli, and suggests, wrongly as $I$ think, that the action is part of the fit, the direct result of the discharging lesion. Notwithstanding the exactness with which it has been found possible to map out the convolutions into motor areas, it must not be concluded that either they, or the deeper parts with which they electrically correspond, are centres capable of initiating the movements which result from their stimulation, or that there exist centres at all for more elaborate acts ; all we can say is that where cerebral activity results in certain movements, the impulses largely pass through certain correspond. ing areas. But these impulses come from no one part of the brain; they are partly sensory, partly reflex, partly volitional, and therefore imply activity of widespread regions, so that although irritation of a motor centre may produce a localised convulsion, it is impossible to conceive that a discharging lesion of any part of the brain could lead to the complex cerebration necessary for the production of the elaborate actions of epileptic automatism. These are, as Dr. H. Jackson has shown, the result of the activity of the remainder, which may have just been " set" to carry out some intention already cerebrally formulated at the moment of suspension of consciousness, or may be directed in certain grooves by sense impressions, either from without or from the viscera, or may be influenced by various subjective sensations produced by the discharge itself. In epileptic attacks conscious. ness departs in various ways, and its total abolition is often preceded by steps of less and less perfect relation to the environment-in other words, by a series of subjective sensa. tions. When these develop slowly and are remembered they form the aura, but it is impossible to say how far into the fit they may extend, and they would be as likely to give rise to automatic action as would external gense impressions. Dr. Hughlings Jackson had a bey under his care who was 